Hydrology and Earth System Sciences, 9(6), 692-698 (2005) C C EGU

\title{
The role of Lake Dongting in regulating the sediment budget of the Yangtze River
}

\author{
Shi-bao Dai ${ }^{1,2}$, Shi-lun Yang ${ }^{1}$, Jun $\mathrm{Zhu}^{3}$, Ang Gao ${ }^{1}$ and Peng $\mathrm{Li}^{1}$ \\ ${ }^{1}$ State Key Laboratory of Estuarine and Coastal Research, East China Normal University, Shanghai, China 200062 \\ ${ }^{2}$ Geography Department, Chuzhou University, Anhui province, China 239012 \\ ${ }^{3}$ Department of Environment, Earth \& Ocean Sciences, University of Massachusetts Boston, Boston, MA 02125-3393, USA \\ Email for corresponding author: slyang@sklec.ecnu.edu.cn; shilungyang@hotmail.com
}

\begin{abstract}
Lake Dongting, the second largest freshwater lake in China and located in the middle reaches of the River Yangtze catchment, was formed at the beginning of the Holocene period by sea level rise and has varied in size with changes in local weather patterns. The sedimentation rate in Lake Dongting during the Holocene is about $50 \times 10^{6} \mathrm{~m}^{3} \mathrm{yr}^{-1}$, or $80 \times 10^{6} \mathrm{t} \mathrm{yr}^{-1}$ (a sand bulk density of $1.6 \times 10^{3} \mathrm{~kg} \mathrm{~m}^{-3}$ ), given the sediment deposition rate as $10 \mathrm{~mm} \mathrm{yr}^{-1}$ and the average lake size as $5000 \mathrm{~km}^{2}$. By comparing the sediment import and export, it is estimated that the

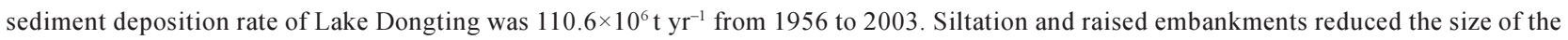
lake and its capacity to accommodate floods. The sediment delivery ratio (SDR) of the middle and lower Yangtze is about 0.92 (total sediment output divided by total sediment input) given that the total sediment supply into the middle and lower Yangtze is $455.1 \times 10^{6} \mathrm{t} \mathrm{yr} \mathrm{r}^{-1}$ and the total sediment discharge into the sea is $419 \times 10^{6} \mathrm{tyr}^{-1}$. Therefore, if it were not for Lake Dongting, the sediment flux at Datong would be $73.6 \times 10^{6}$

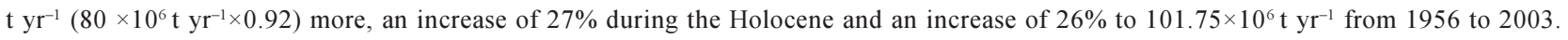
Historically, Lake Dongting had a considerable influence in regulating the sediment budget of the Yangtze. However, afforestation and the construction of large dams, such as the Three Gorges Dam, reduced significantly the sediment deposition in Lake Dongting. In 2003, the completion of the Three Gorges Dam and the subsequent impoundment of water reduced the sediment input from the Yangtze and net deposition in Lake Dongting dropped to $25 \%$ and $18 \%$ of the mean values of the historic records (1956-2003). During the same period, the amount of sediment deposited in Lake Dongting was only $10 \%$ of the sediment discharge at Datong. The influence of the sediment deposited in Lake Dongting on the sediment flux to the sea from the Yangtze has fallen since the completion of the Three Gorges Dam and will be further reduced in future. The evolution of the relationship between Lake Dongting and the Yangtze is a compound result of human impacts coupled with natural self-adjusting processes in the river system.
\end{abstract}

Keywords: deposition, sediment budget, sediment delivery ratio, Lake Dongting, Yangtze River, human activity

\section{Introduction}

River sediment fluxes are sensitive to many influences, including reservoir construction, land clearance, land-use change, mining activity, soil and water conservation measures, sediment control programmes and climate change (Walling and Fang, 2002). In many cases, only a small proportion of the soil eroded within a river basin reaches the outlet (Walling et al., 1998); much will be deposited close to the erosion area, at the foot of slopes, in small tributaries, or on flood plains bordering the main channel (Li et al., 1999). The sediment deposited in the river system affects not only the river morphology but also the interpretation of the sediment yield in the river basin and the sediment flux to the sea (Chen et al., 1998; Walling et al., 1998).

Sediment budgets in drainage systems are important in understanding the drainage morphology process (Sutherland and Bryan, 1991) and are an interesting research topic, attracting the attention of both geomorphologists and hydrologists (Walling et al., 1998). Such budgets have been constructed at scales ranging from a small catchment (Demissie, et al., 2003; Simon et al., 1997; Owens et al., 1997; Walling et al., 1998, 2002) to a large river basin (Meade, 1982; Shi, 2003). Previous studies focused mainly 
on sediment storage in channels and on flood plains (Walling et al., 1998; Fryirs and Brierley, 2001), or in wetlands along river courses (Zierholz et al., 2001; Arp and Cooper, 2004). Few researchers took estuaries into account (Fryirs and Brierley, 2001). Likewise, the Yangtze River catchment has been studied (Liu and Zhang, 1995; Zhang and Wen., 2002; Wan et al., 2003; Yi, 2003; Yin et al., 2004). Dam construction and afforestation in the Yangtze catchment has resulted in a marked reduction in the sediment discharge of the Yangtze in the past decade; this decrease in sediment supply has reduced the accretion rate of the subaqueous front of theYangtze delta, so that delta recession in the next 50 years is likely (Yang et al., 2003; Yang et al., 2004).

This paper investigates the role of Lake Dongting in regulating the sediment budget of the Yangtze River. In particular, it considers the evolution of Lake Dongting and the temporal changes in its influence on the sediment budget of the Yangtze River and its estuary.

\section{Physical setting}

The Yangtze River is $6380 \mathrm{~km}$ long and its catchment area is about $1.91 \times 10^{6} \mathrm{~km}^{2}$. The average annual water discharge is $918 \mathrm{~km}^{3}$ and the average annual load of suspended sediment is $419 \times 10^{6} \mathrm{t}(1956-2003)$, respectively the fifth and fourth largest in the world (Milliman and Meade, 1983; Milliman and Syvitski, 1992) (Fig. 1). Lake Dongting is the second largest freshwater lake in China. It lies in the middle reaches of theYangtze River, about $400 \mathrm{~km}$ downsteam of the Three Gorges Dam (TGD) and $1400 \mathrm{~km}$ away from the river mouth. Lake Dongting has four tributaries: the Rivers Xiangjiang, Zishui, Yuanjiang and Lishui,. collectively called the Four Rivers. Three Channels (Fig. 1) connect Lake Dongting to the Yangtze. In the flood season, when water from the Yangtze pours into the lake through these channels, the velocity of the water drops and a major proportion of the sediment suspended in the flood water is deposited in the lake, reducing substantially the sediment load in the Yangtze downstream. Therefore, Lake Dongting plays a very important role not only in accommodating flood waters but also in regulating the sediment supplied to the lower reaches as well as to the estuary of the Yangtze River system.

\section{Material and methods}

The data on water and sediment fluxes were provided by the Yangtze River Water Conservancy Committee, Ministry of Water Conservancy of China that began systematic (daily) surveys in the 1950s in the Yangtze drainage basin. Previous studies on the Yangtze (Yang et al., 2004; Chen et al., 2005) were based on this data set. Data from the gauging stations in the tributaries and channels that connect the Yangtze to Lake Dongting have been used to estimate sediment deposition rate before and after the completion of the TGD. Sediment budget is based on a data set of sediment flux of the main tributaries in the mid-lower reaches of the Yangtze. The velocity of tectonic subsidence of Lake Dongting from the Holocene onwards has been used to determine the amount of sediment deposited in the lake, by multiplying the velocity by the area of the lake.
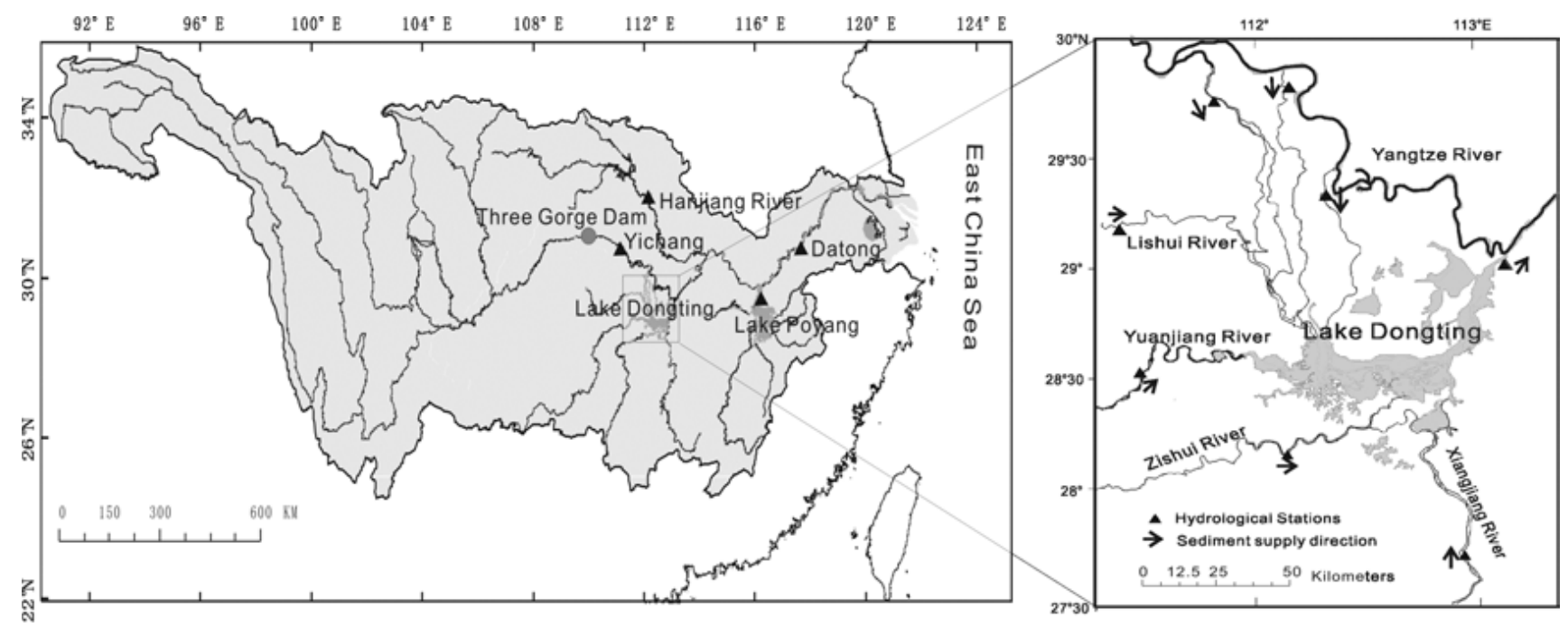

Fig. 1. A sketch map showing Lake Dongting and Yangtze drainage basin 


\section{Results and discussions}

\section{THE HISTORICAL EVOLUTION AND}

\section{SEDIMENTATION OF LAKE DONGTING}

Since the Holocene, the evolution and sediment deposition pattern of Lake Dongting can be divided into three stages. The first was from 8000 to 2000 B.P. when the Yangtze River basin was sparsely populated. Soil erosion was slight and sediment accretion was slow. The size of the lake was determined by changes in the local weather pattern. The second stage was from 2000 B.P. to 1998 when the human population increased in the Yangtze basin. Soil erosion accelerated and rapid sediment accretion occurred. The size of the lake decreased due to the influences of climatic change and human activities. In the past century, intensified embankment and reclamation of Lake Dongting, along with strong sedimentation following severe deforestation in the upper reaches of the Yangtze basin, has resulted in rapid reduction in the size of the lake. From the 1820 s to the 1990 s, more than half of the lake area disappeared (Fig. 2). The third stage is from 1998 to the present. After a large flood event in 1998, the inundation of much of the land reclaimed from the lake increased the capacity of the lake to accommodate sediment; the lake area was 35\% greater than that in 1995 and reached $3177 \mathrm{~km}^{2}$ in 2001 (Fig. 2).

The survival of Lake Dongting despite strong siltation is mainly attributed to tectonic subsidence of about 3-10 $\mathrm{mm} \mathrm{yr}^{-1}$ since the Holocene (Zhang et al., 2000). Even so, the rate of sedimentation in the lake exceeds that of the tectonic subsidence of the lake, which is evident from sandbar growth. Given the sediment deposition rate as $10 \mathrm{~mm} \mathrm{yr}^{-1}$ and the average lake size as $5000 \mathrm{~km}^{2}$, the sedimentation rate in Lake Dongting is about $50 \times 10^{6} \mathrm{~m}^{3} \mathrm{yr}^{-1}$, or $80 \times 10^{6} \mathrm{t} \mathrm{yr}^{-1}$ (a sand bulk density of $1.6 \times 10^{3} \mathrm{~kg} \mathrm{~m}^{-3}$ ). As the sediment flux of the Yangtze to the sea was about $240 \times 10^{6} \mathrm{t} \mathrm{yr}^{-1}$ in the Holocene (Hori et al., 2001; Li et al., 2002), the sediment deposited in Lake Dongting is about one-third of the total sediment supply reaching the river mouth. This ratio is lower than that estimated by Hori et al.(2001) and is equal to that calculated by Chen and Zhao (2001). As a depository, Lake Dongting significantly reduced the sediment discharge into the lower part of the Yangtze as well as into the sea.

\section{SEDIMENTATION OF LAKE DONGTING IN THE PAST FIVE DECADES}

The average deposition rate in Lake Dongting is $110.6 \times 10^{6}$

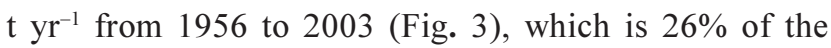
sediment discharge at the Datong station. The total water discharge into Lake Dongting dropped by nearly $20 \%$ between 1991 and 1998 compared with the value between 1951 and 1960. The total sediment discharge into the lake decreased significantly by about $63 \%$, from $264.15 \times 10^{6}$

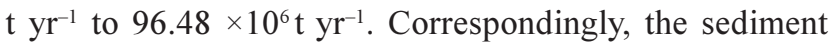
trapped in the lake decreased by $56 \%$, from $188.45 \times 10^{6}$

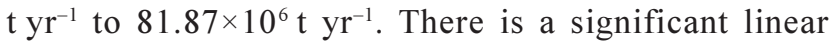
correlation between sedimentation in Lake Dongting and the sediment supply from the Three Channels, which contributed $80 \%$ of the total sediment discharge into Lake Dongting (Fig. 4). From 1981-1990 to 1991-1998, the water supply from three channels decreased by $18 \%$ and the sediment supply by $27 \%$. It is suggested that the decline in the sediment supply from the Three Channels leads to the decrease in the water supply due to natural and anthropogenic cutoffs in the main stream (Li et al, 1995).

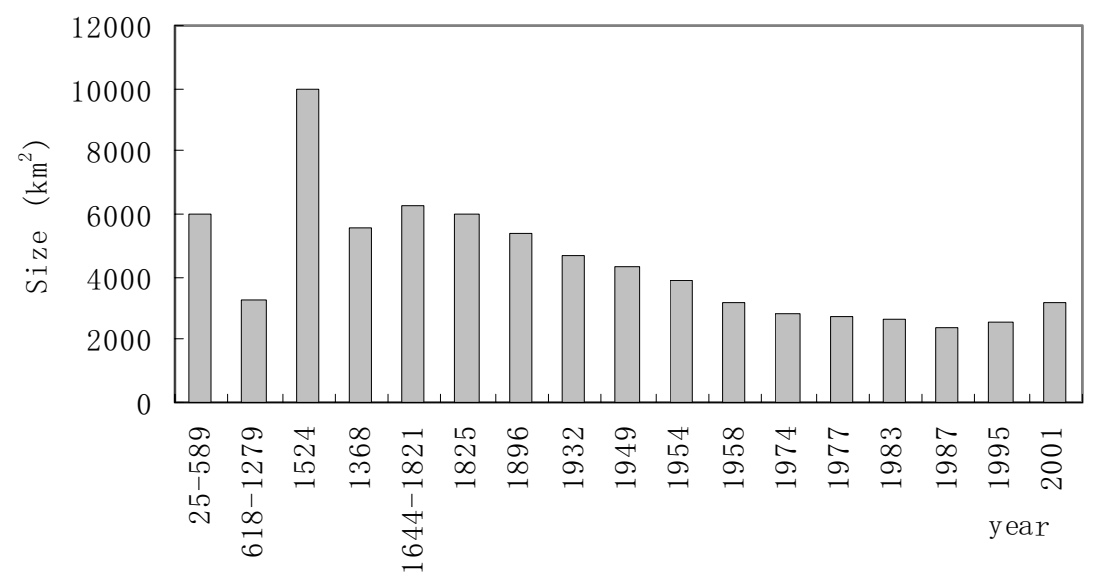

Fig. 2. The variation in size of the Lake Dongting in the past 2000 years (Data source: Wang et al., 1998; Chen and Yang, 2000; Zhou, 2001; http:www.chinadaily.com.cn/en/doc/2003-03/04/content_156675.htm, 2004-5-24; http://www.wetland.gov.cn/plant/plant03nishayangzhong.htm, 2004) 


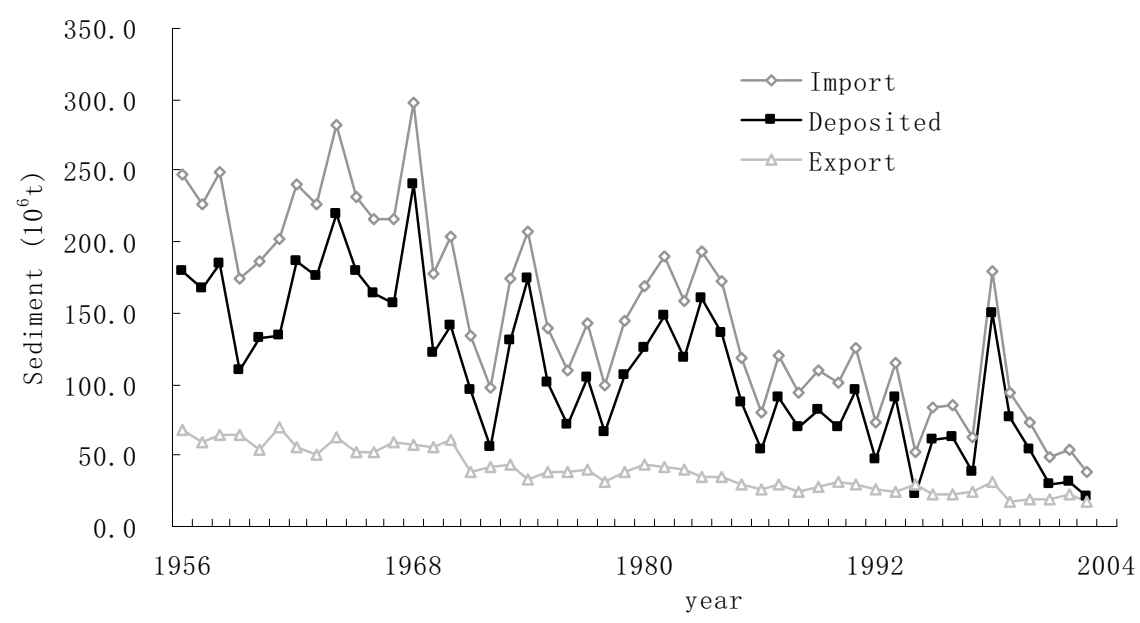

Fig. 3. Annual sediment budget of Lake Dongting from 1956 to 2003

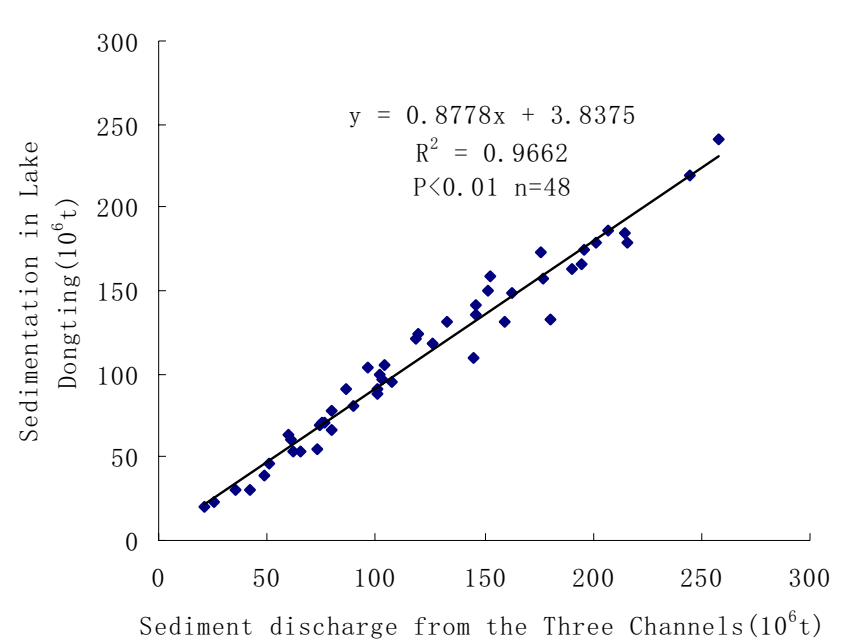

Fig. 4. Significant linear correlation between sedimentation in Lake Dongting and sediment discharge from the Three Channels
The mean sediment load of the Yangtze at Yichang decreased from $1.22 \mathrm{~kg} \mathrm{~m}^{-3}$ to $0.92 \mathrm{~kg} \mathrm{~m}^{-3}$ (about 25\%) between 1981-1990 and 1991-1998. Hence, the main cause of sedimentation decline in Lake Dongting may have been the coincidence of a reduced sediment load in the main channel of the Yangtze with a decrease in the capacity of Lake Dongting.

\section{REGULATION EFFECT OF LAKE DONGTING IN} THE SEDIMENT BUDGET OF THE YANGTZE

Tributaries below the Yichang station include the Lake Dongting basin, the River Hanjiang and the Lake Poyang basin, which has five local tributaries. An estimated sediment budget of the middle and lower Yangtze has been based on a data set from 1956 to 2003 (Fig. 5). The total sediment supply to the middle and lower Yangtze is $455.1 \times 10^{6} \mathrm{t} \mathrm{yr}^{-1}$ and the total sediment discharge into the sea is $419 \times 10^{6}$

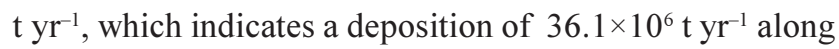

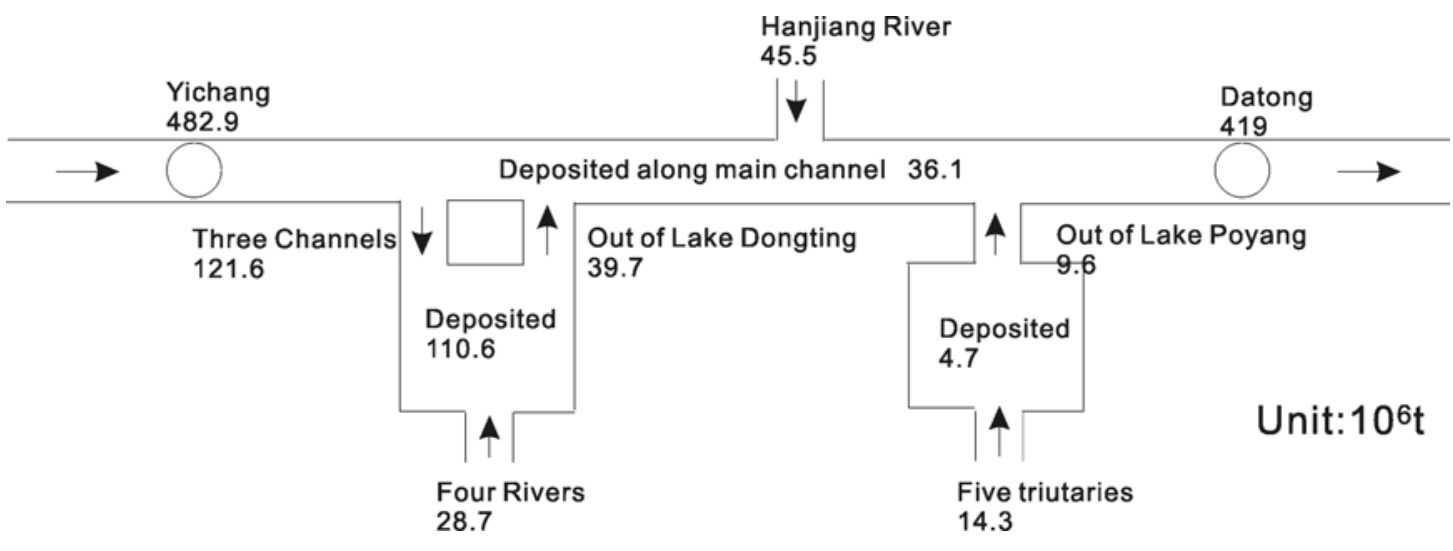

Fig. 5 Sediment budget in the middle and lower Yangtze River 


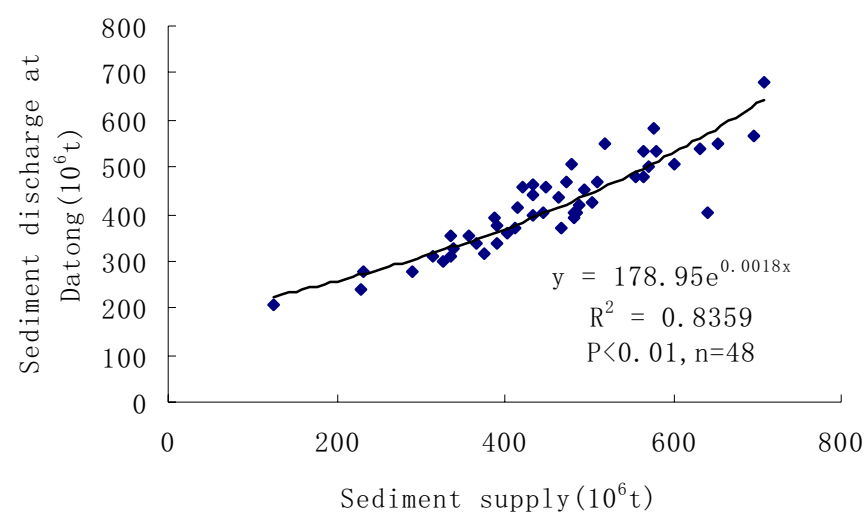

Fig. 6. Relationship between sediment discharge at Datong station and the total sediment supply to the middle and lower reaches of Yangtze River

the river channel. If the sediment deposition in Lake Dongting is not taken into account, the sediment delivery ratio (SDR) of the middle and lower Yangtze would be 0.92 . Statistical analysis shows that sedimentation in Lake Dongting has significant linear correlation with the sediment discharge of the Yangtze River (Fig. 6). Without the sediment deposition in Lake Dongting, on average, more than
$110.6 \times 10^{6} \mathrm{t}$ sediment would be carried down to the lower Yangtze River in a year. Most of it, about $110.6 \times 10^{6} \mathrm{t} \mathrm{yr}^{-1}$ $\times \operatorname{SDR}(0.92)=101.75 \times 10^{6} \mathrm{t} \mathrm{yr}^{-1}$, will be transported into the estuary and the rest would be deposited in the river channel. Without the sediment deposition in Lake Dongting, the time series of sediment discharge at Datong station would likely be the same as the upper one shown in Fig. 7. Needless to say, Lake Dongting plays a very important role in regulating the sediment budget of the Yangtze River system.

\section{NEW TRENDS IN SEDIMENTATION OF LAKE DONGTING}

Different predictions have been made in terms of the response of Lake Dongting to the Three Gorges Dam (Wang and Han, 1997; Qin et al., 1998; Chen et al., 2003). The completion of the Three Gorges Dam and impoundment of water began in June, 2003, which trapped about 0.1 billion tons of sediment from June to September (Dai et al., 2005). Although the water discharge has decreased by only $8.6 \%$ of the mean value of 1956-2003 through the Three Channels, sediment supply to Lake Dongting decreased sharply (Table 1) to only $25 \%$ over the same period. Correspondingly, the absolute sediment deposition

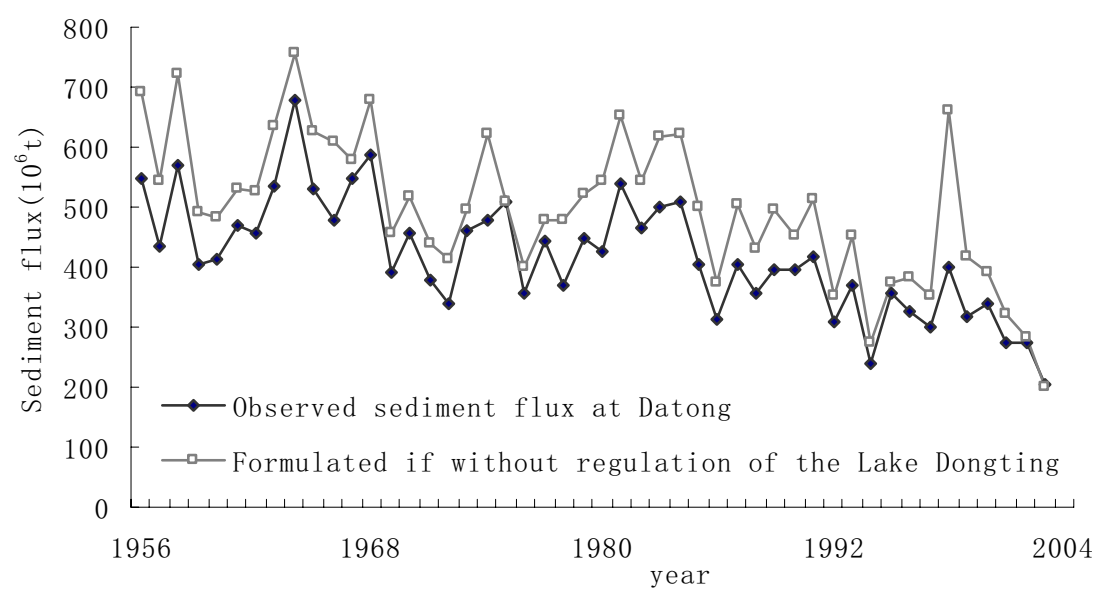

Fig. 7. Regulating effects of Lake Dongting on the sediment flux at Datong station

Table 1. Comparison of water discharge and sediment load in Lake Dongting in different time scales (Time scale for the average water discharge and sediment load is 1951-1998 and 1956-2003, respectively)

\begin{tabular}{|c|c|c|c|c|c|c|c|c|}
\hline \multirow[t]{2}{*}{ YEAR } & \multicolumn{3}{|c|}{ WATER DISCHARGE $\left(10^{9} \mathrm{M}^{3}\right)$} & \multicolumn{4}{|c|}{ SEDIMENT LOAD $\left(10^{6} \mathrm{~T}\right)$} & \multirow[b]{2}{*}{ Deposited } \\
\hline & $\begin{array}{l}\text { Three } \\
\text { Channels }\end{array}$ & $\begin{array}{l}\text { Four } \\
\text { Rivers }\end{array}$ & Total & $\begin{array}{l}\text { Three } \\
\text { Channels }\end{array}$ & $\begin{array}{l}\text { Four } \\
\text { Rivers }\end{array}$ & Total & Out of lake & \\
\hline 2001 & 61.5 & 168.5 & 230.0 & 35 & 6.6 & 41.6 & 23 & 18.6 \\
\hline 2003 & 100.5 & 171.5 & 272.0 & 20.7 & 17.8 & 38.3 & 17.5 & 20.8 \\
\hline Average & 129.4 & 168.5 & 297.9 & 121.6 & 28.7 & 150.3 & 39.73 & 110.6 \\
\hline
\end{tabular}




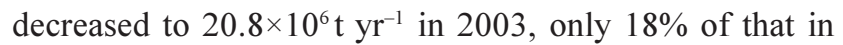
1956-2003. This is consistent with the predictions of Wang and Han (1997) and Qin et al. (1998). Compared to 2001, water discharge from the Three Channels increased $18 \%$ in 2003, while sediment discharge decreased by $12 \%$. The sediment deposition in Lake Dongting in 2003 is only 10\% of the sediment discharge at Datong station in the same time, much lower than the mean value, $26 \%$, for $1956-2003$. If the sediment deposition rate in the lake is the same as at present, $20.8 \times 10^{6} \mathrm{t} \mathrm{yr}^{-1}$, and the size of the lake remains as in $2001\left(3177 \mathrm{~km}^{2}\right)$, the average sediment accretion rate at the bottom of the lake would be $4.7 \mathrm{~mm} \mathrm{yr}^{-1}$, much lower than the present tectonic subsidence rate, which is about $10 \mathrm{~mm} \mathrm{yr}^{-1}$. Enlargement of the accommodation capacity and lake size would be needed, although less sediment would be trapped in future. The influence of sediment deposition in Lake Dongting on the sediment flux of the Yangtze to the sea is expected to be less in future.

\section{Conclusion}

Located below the upper reaches of the Yangtze basin and in a tectonic subsidence area, Lake Dongting accommodated not only floods from the upper reaches but also played an important role in regulating the sediment budget of the Yangtze system. The sediment deposition rate in Lake Dongting was $80 \times 10^{6} \mathrm{t} \mathrm{yr}^{-1}$ during the Holocene and was $110.6 \times 10^{6} \mathrm{t} \mathrm{yr}^{-1}$ from 1956 to 2003 . Were it not for the deposition in Lake Dongting, the sediment flux at Datong would be $73.6 \times 10^{6} \mathrm{t} \mathrm{yr}^{-1}\left(80 \times 10^{6} \mathrm{t} \mathrm{yr}^{-1} \times 0.92\right)$ more, a $27 \%$ increase during the Holocene and a $26 \%$ increase to $101.75 \times 10^{6} \mathrm{t} \mathrm{yr}^{-1}$ between 1956 and 2003.

The evolution of Lake Dongting and the changes in its capacity to accommodate flood waters and sediment have, in the past, greatly influenced the sediment budget of the Yangtze. The campaign to return land to the lake after a major flood in 1998 as well as the consequences of afforestation in the catchment and dam constructions along the Yangtze, have increased the capacity of Lake Dongting to accommodate floods and much less sediment was trapped than previously. The Three Gorges Dam greatly reduced the sediment supply from the Yangtze and, consequently, reduced the sediment deposition in Lake Dongting. The influence of sediment deposition in the lake on the sediment flux of the Yangtze to the sea will be further reduced in future. Further studies, such as responses of ecosystems along the river course (including the evolution of Lake Dongting) and responses of the delta, as are well documented for the Nile (Fanos, 1995), the Colorado (Carriquiry, 1999), the Ebro (Mikhailova, 2003), and the Yellow River (Xu, 2003), are scientifically significant and crucial.

\section{Acknowledgements}

This research was jointly supported by the Ministry of Education of China (No. PCSIRT0427) and the Ministry of Science and Technology of China (No. 2002CB412407). Prof. Jing Zhang is thanked for his kindness in providing the data set. Managing Editor J.S.G. McCulloch and the anonymous reviewers are thanked for their comments and help in improving the manuscript.

\section{References}

Arp, C.D. and Cooper, D.J., 2004. Analysis of sediment retention in western riverine wetlands: the Yampa River watershed, Colorado, USA. Environ. Manage., 3, 318-330.

Carriquiry, J.D. and Sanchez, A., 1999. Sedimentation in the Colorado River delta and Upper Gulf of California after nearly a century of discharge loss. Mar. Geology, 158, 125-145.

Chen Guosheng andYang Gang, 2000. Reflections of historical geography on the floods and the changes of ecological environment along the Changjiang river valley. Yunnan Geogr. Environ. Res., 12, 31-36 (in Chinese with an English abstract).

Chen Jiyu, Yun Caixing, Xu Haigen, et al., 1998. The model of development of the Changjiang Estuary during the last 2000 years. In: Progress of Dynamics and Geomorphology of the Changjiang Estuary Shanghai, Chen Jiyu, Shen Huanting, Yun Caixing et al. (Eds), Shanghai Scientific and Technical Publishers, 31-37 (in Chinese).

Chen Li, Wu Menwu and Zhang Junyong, 2003. Effect of the Three Gorges project on sediment transportation of the Yangtze estuary. Resour. Environ. Yangtze Basin, 12, 50-54 (in Chinese with an English abstract).

Chen Xiqing, Zhang Erfeng, Mu Hongqiang and Y. Zong, 2005. A preliminary analysis of human impacts on sediment discharges from the Yangtze, China, into the Sea. J. Coast. Res., 21, 515521.

Chen Zhongyuan and Zhao Yiwen, 2001. Impact on the Yangtze (Changjiang) estuary from its drainage basin: sediment load and discharge. Chin. Sci. Bull., 46 supp, 73-80.

Dai, S.B., Yang, S.L., Li, M., Zhao, H.Y., Yu, Z.Y., 2005. Response of middle and lower reaches of Yangtze River to the Three Gorges Dam in its initial stage of operation. J. Sediment Res, $\mathbf{5}$, 52-57(in Chinese with an English abstract)

Fanos, A.M., 1995. The impact of human activities on the erosion and accretion of the Nile delta coast. J. Coast. Res., 11, 821-833.

Fresh water lakes recovering. http:www.chinadaily.com.cn/en/doc/ 3003-03/04/content_156675.htm. 2004-5-24.

Fryirs, K. and Brierley, G.J., 2001.Variability in sediment delivery and storage along river courses in Bega catchment, NSW, Australia: implications for geomorphic river recovery. Geomorphology, 38, 237-265.

Hori Kazuaki, Saito Yoshiki, Zhao Quanhong et al., 2001. Progradation of the Changjiang river delta since the midHolocene. Sci. China (Ser. B), 44 supp., 87-91.

http://www.wetland.gov.cn/plant/plant03-nishayangzhong.htm, 2004,4-29

Li Baohua, Li Congxian and Shen Huanting, 2002. A preliminary study of the sediment flux of Yangtze delta after the Ice Age. Sci. China (Ser. D), 32, 776-782 (in Chinese with an English abstract). 
Li Chang-an, Yin Hong-fu and Yu Li-Zhong, 1999. Silt transform characteristics and latent effect on fluvial system environment in Yangtze river. Resour. Environ. Yangtze Basin, 9, 504-509 (in Chinese with an English abstract).

Liu Yi and Zhang Ping, 1995. Surface erosion in upper Yangtze Region and river sediment transport. J.Yangtze River Sci.Res. Inst., 12, 40-44.

Meade, R.H., 1982. Sources, sinks, and storage of river sediment in the Atlantic drainage of the United States. J. Geol., 90, 235252

Mikhailova M.V. , 2003. Transformation of the Ebro river delta under the impact of intense human-induced reduction of sediment runoff. Water Resour. Res., 30, 370-378.

Milliman, J.D. and Meade, R.H., 1983. World-wide delivery of river sediment to the oceans. J. Geol., 91,1-21.

Milliman, J.D. and Syvitski, J.P.M., 1992. Geomorphic/tectonic control of sediment discharge to the ocean: the importance of small mountainous rivers. J. Geol., 100, 525-544.

Owens, P.N., Walling, D.E., He, Q., Shanahan, J. and Foster, I.D.L., 1997. The use of caesium-137 measurements to establish a sediment budget for the Start catchment, Devon, UK. Hydrolog. Sci. J., 42, 405-423.

Qin Wenkai, Fu Renshou, Wang Chonghao, et al., 1998. Silting of Dongting Lake before and after completion of the Three Gorges Project. J. Tsinghua Univ. (Sci. and Tech.), 38, 84-87 (in Chinese with an English abstract).

Shi Changxing, 2003. Sediment budget of the Yellow River over the period 1855-1968. J. Sediment Res., 2, 1-6.

Simon, J.W., Trevor, B.H. and Alan, W., 1997. Quantitative determination of the activity of within-reach sediment storage in a small gravel-bed river using transit time and response time. Geomorphology, 20,113-134.

Sutherland, R.A. and Bryan, R.B., 1991. Sediment budgeting: a case study in the Katiorin Drainage basin, Kenya. Earth Surf. Process. Landf., 16, 383-398.

Walling, D.E. and Fang, D., 2003. Recent trends in the suspended sediment loads of the world rivers. Global and Planetary Change, 39,11-126.

Walling, D.E., Owens, P.N. and Leeks, G.J., 1998. The role of channel and floodplain storage in the suspended sediment budget of the River Ouse, Yorkshire, UK. Geomorphology, 22, 225242.

Walling, D.E., Russell, M.A., Hodgkinson, R.A. et al. 2002. Establishing sediment budgets for two small lowland agricultural catchments in the UK. Catena, 47, 323-353.
Wang Chonghao and Han Qiwei, 1997. Estimate of aggregation and degradation in the Dongting Lake and the flood diversion channels of the Jingjiang River after the Three Gorges reservoir being built. Water Resour. Hydropower Eng., 28, 16-20 (in Chinese with an English abstract).

Wang Jian, Wang Xiaolong, Chen Zhiliang et al., 1998. The evolution of the fluvial-lacustrine systems and protection and control of catastrophic floods along the Yangtze River. Sediment. Facies Palaeogeogr., 18, 1-9 (in Chinese with an English abstract).

Wan Xinning, Li Jiufa and He Qing, 2003. Water and sediment fluxes in the middle and lower Yangtze River. J. Sediment Res., 4, 29-35 (in Chinese with an English abstract).

$\mathrm{Xu}$ Jionxin, 2003. Sediment Flux to the Sea as Influenced by Changing Human Activities and Precipitation: Example of the Yellow River, China. Environ. Manage., 31, 328-341.

Yang, S.L., Belkin, I.M., Belkina, A.I. et al., 2003. Delta Response to Decline in Sediment Supply from the Yangtze River: Evidence of the Recent Four Decades and Expectations for the Next HalfCentury. Estuar. Coast. Shelf Sci., 57, 589-599.

Yang, S.L., Shi, Z., Zhao, H.Y., Li, P., Dai, S.B. and Gao, A., 2004. Effects of human activities on the Yangtze River suspended sediment flux into the estuary in the last century. Hydrol. Earth Syst. Sci., 8, 1210-1216.

Yangtze River sediment report 2000a2004.5.23. http:// www.cjh.com.cn/singleSubject.asp?filetype $=$ da

Yi Zhewen, 2003. Sediment in up reaches of Yangtze River. Sichuan Hydrol., 5, 29-33.

Yin Hongfu, Chen Guojin, Li Changan et al., 2004. Sedimentation in the middle reaches of Yangtze River. Sci. China (Ser. D), 34, 195-209 (in Chinese).

Zhang Ren-quan, Liang Xing, Chen Guo-jin et al., 2000. The evolution of geo-environmental system of middle reaches basin of Yangtze river and the strategies for flood prevention. Resour. Environ. Yangtze Basin, 9, 104-111 (in Chinese with an English abstract)

Zhang Xinbao and Wen Anbang, 2002. Variations of sediment in upper stream of Yangtze River and its tributary. J. Hydraul. Eng., 4, 56-59.

Zhou Kuiyi, 2001. Historical development and flood control function evaluation in Dongting Lake. J. Heilongjiang Hydraul. Eng. College, 28, 1-7 (in Chinese with an English abstract).

Zierholz, C., Prosser, I.P., Fogarty, P.J. et al., 2001.In-stream wetlands and their significance for channel filling and the catchment sediment budget, Jugiong Creek, New South Wales. Geomorphology, 38, 221-235. 